\title{
Physical workload and thoughts of retirement
}

\author{
Perkiö-Mäkelä, Merja ${ }^{a^{*}}$ and Hirvonen, Maria ${ }^{\mathrm{a}}$ \\ ${ }^{a}$ Finnish Institute of Occupational Health, Kuopio, Neulaniementie 4, box 310, 70101 Kuopio, Finland,
}

\begin{abstract}
The aim of this paper is to present Finnish employees' opinions on continuing work until retirement pension and after the age of 63, and to find out if physical workload is related to these opinions. Altogether $39 \%$ of men and $40 \%$ of women had never had thoughts of early retirement, and $59 \%$ claimed (both men and women) that they would consider working beyond the age of 63 . Own health $(20 \%)$; financial gain such as salary and better pension (19\%); meaningful, interesting and challenging work (15\%); flexible working hours or part-time work (13\%); lighter work load (13\%); good work community $(8 \%)$; and good work environment $(6 \%)$ were stated as factors affecting the decision to continue working after the age of 63. Employees whose work involved low physical workload had less thoughts of early retirement and had considered continuing work after the age of 63 more often than those whose work involved high physical loads. Own health in particular was stated as a reason to consider continuing work by employees whose work was physically demanding.
\end{abstract}

Keywords: retirement intentions, postponing retirement, physically demanding work, work posture

\section{Introduction}

Many countries in the European Union have either implemented or planned pension reforms with the objective of extending work life by two to three years. In Finland, the reform of the earnings-related pension system came into force in 2005 , offering economic incentives to continue working after the age of 63. In the private sector, retirement is flexible, and can begin between the ages of 63 and 68. For state and local government employees however, the retirement age may be lower than 63. Presently, the average expected age of retirement is 60.4 for those currently aged 25, and 62.3 for those now aged 50 [1].

High physical work demands and heavy physical work have been found to associate with early retirement $[2,5]$, but there are few studies on this.

\section{Objectives}

The aim of this paper is to examine Finnish employees' opinions on continuing work until the official old age retirement pension and after the age of 63 , and to find out whether physical workload is related to these opinions.

"Corresponding author. E-mail: merja.perkio-makela@ttl.fi

\section{Methods}

This study is part of the Finnish national Work and Health survey, which has been conducted every three years by the Finnish Institute of Occupational Health since 1997. The subjects were a random sample of the Finnish population, aged 25-64. We obtained the information on the population from the 2009 Finnish Employment Statistics and the 1997-2006 Finnish Population Register. Here, we use the data from the Work and Health surveys 2006 and 2009. The response rate was $63 \%$ in 2006 and $59 \%$ in 2009 . Retired, unemployed, or redundant (over one month) subjects, those on long-term sick leave (over six months), full-time housewives or househusbands, and students who worked less than 15 hours a week were excluded from our survey. The size of the study population was 2229 in 2006, and 2355 in 2009. The respondents were representative of the Finnish working-age population with reference to sex, age, occupation and socioeconomic status (based on occupation and occupational status), and region. [3, 4].

We elicited retirement intentions from employees aged 45-64 in 2006 and 2009. These data were combined in the analysis. The final study group included 2103 currently working employees aged 45 to 63 . 
The data were collected through computer-assisted telephone interviews (CATI), the average length of which was 36 minutes. The structure of the interview was planned by a group of experts at the Finnish Institute of Occupational Health [4], and included questions on demographic and socioeconomic background, workload, and retirement intentions. Socioeconomic status was trichotomized into upper and lower white-collar employees and manual workers.

\subsection{Dependent variables}

Retirement intentions were elicited by two separate questions:

1. Have you ever considered retiring before the official retirement age due to health or other reasons? The answers were categorized into two classes:

1. No

2. Yes, I have thought about it sometimes/often/I have already applied for retirement

2. The objective of the Ministry of Social Affairs and Health is to improve working conditions and workers' health so that people can continue in work life for longer. What factors would motivate you to continue working beyond the age of 63 ? State the factors that would make you consider working after the age of 63 . (The interviewers were forbidden to give hints regarding possible answers, and the interviewee was allowed to give several answers.) The responses were categorized into the following groups:

- Own health (no/yes)

- Financial gain (higher level of occupational pension, salary) (no/yes)

- Working hours (flexible hours, parttime work, reduction in working hours) (no/yes)

- Meaningful, interesting and challenging work (opportunity to exert influence, gain respect, work as part of life) (no/yes)

- Lighter workload (reduction in amount of work, age taken into consideration, reduction in physical and mental loading of work) (no/yes)

- Good work community (e.g. good social relations at work, good management, good atmosphere at work, enjoyment of work) (no/yes)
- Good work environment (no/yes)

- Other, what (no/yes)

- Nothing

If the person gave any of these reasons, she/he was categorized as considering working beyond the age of 63 .

\subsection{Physical workload}

Physical workload was assessed through questions on the physical strain of the work, work postures, lifting and carrying, and how practical and welldesigned worksites were.

We classified the answers into three categories, of which category 1 described low physical workload, 2 moderate physical workload, and 3 high physical workload.

- Is your work physically 0) light/fairly light; 1) somewhat demanding; 2) fairly demanding/very demanding.

- Is the nature of your work mainly 0) alternating between walking/standing/sitting; 1) sitting; 2) standing/walking.

- Does you work involve lifting and carrying with your hands without lifting devices 0) not at all; 1) every now and then/weekly/daily; 2) many times per day/many times per hour

- Does your work involve

- holding your back bent forward or in an awkward posture

- holding your upper limb(s) above shoulder level

- using hand force i.e. cutting, screwing, twisting or moving heavy things

- repetitive hand movements (line work, assembling work, packing work). This question does not cover keyboard work.

Classification for work postures were: 0) not at all; 1) occasionally/almost every day/every day for less than 1 hour; 2) every day for at least 1 to 2 hours

- Are the worksites where you mostly work practical and well-designed from the viewpoint of the fluency of work: 0) yes; 1) not always; 2) not fully.

A sum variable of physical workload was constructed, based on eight items. The value of the sum variable varied theoretically from 0 to 24 and in this study between 0 and 16 . Values $0-3$ indicated low physical workload, values 4-7 moderate workload, and values 8-16 high physical workload (Table 1). 
Table 1

Physical workload among 45-63 year old employees (sum score, range 0-16) in relation to thoughts of retirement. Logistic regression model, odds ratio (OR) and 95\% confidence intervals (CI) adjusted for age, gender and the year of data collection.

\begin{tabular}{|c|c|c|c|}
\hline \multirow[t]{3}{*}{ Thoughts of retirement - reasons to consider continuing work } & \multicolumn{3}{|c|}{ Physical workload (sum score) } \\
\hline & low & moderate & high \\
\hline & (0-3 points) & (4-7 points) & (8-16 points) \\
\hline No thoughts of early retirement & 1 & $0.92(0.74-1.15)$ & $0.54(0.44-0.67)$ \\
\hline Some reason to continue working beyond the age of 63 & 1 & $0.72(0.58-0.90)$ & $0.61(0.50-0.75)$ \\
\hline Own health & 1 & $1.29(0.98-1.69)$ & $1.36(1.05-1.75)$ \\
\hline Financial gain & 1 & $0.97(0.74-1.27)$ & $0.67(0.51-0.87)$ \\
\hline Meaningful, interesting and challenging work & 1 & $0.53(0.40-0.72)$ & $0.27(0.20-0.38)$ \\
\hline Working hours & 1 & $0.57(0.41-0.79)$ & $0.52(0.38-0.71)$ \\
\hline Lighter workload & 1 & $0.92(0.66-1.28)$ & $0.89(0.65-1.21)$ \\
\hline Good work community & 1 & $1.00(0.68-1.48)$ & $0.71(0.48-1.04)$ \\
\hline Good work environment & 1 & $1.11(0.71-1.74)$ & $0.78(0.49-1.22)$ \\
\hline
\end{tabular}

\subsection{Statistical methods}

We combined the data from 2006 and 2009 for the analyses and used logistic regression to assess the associations between physical workload and opinions on retirement. Odds ratios and their $95 \%$ confidence intervals were adjusted for age, gender and year of data collection. The analysis was carried out using SAS software (version 9.2).

\section{Results}

Altogether $39 \%$ of the men and $40 \%$ of the women had never thought of early retirement (adjusted for age). This was less among manual workers (33\%) than among upper (46\%) and lower white-collar employees (41\%) (adjusted for age and gender).

A total of $59 \%$ claimed (both men and women) that they would consider working beyond the age of 63 (adjusted for age). This was less among manual workers $(50 \%)$ than among upper $(68 \%)$ and lower white collar employees $(60 \%)$ (adjusted for age and gender).

Own health (20\%); financial gain, such as salary and better pension (19\%); meaningful, interesting and challenging work (15\%); flexible working hours or part-time work $(13 \%)$; lighter workload (13\%), good work community $(8 \%)$ and good work environment $(6 \%)$ were stated as reasons for considering continuing work after the age of 63 .

Two in three employees $(65 \%)$ considered the worksites at which they mainly worked functional and practical. One in four $(26 \%)$ employees considered his/her work to be somewhat or very physically straining, 37\% mainly stood or walked during their working day, and $24 \%$ of employees lifted or carried without lifting devices many times per day. One in four $(23 \%)$ employees reported awkward back postures, $11 \%$ worked with their upper $\operatorname{limb}(\mathrm{s})$ above shoulder level, 15\% used hand force and 29\% repetitive hand movements for at least one to two hours per day.

Employees whose work involved low physical workload more seldom had thoughts of early retirement, and had more often considered continuing work after the age of 63 than those with a high physical workload (Table 1).

Own health in particular was stated as a reason to consider continuing at work by employees with a high physical workload. Financial gain; meaningful, interesting and challenging work; and flexible working hours were common factors for employees with a low physical workload (Table 1). 


\section{Discussion}

The aim of this study was to examine Finnish employees' opinions on continuing work until the official old age retirement pension and after the age of 63 , and to find out whether physical workload was related to these opinions. Employees whose work involved a low physical workload more seldom had thoughts of early retirement and had more often considered continuing work after the age of 63 than those with a high physical workload. The reasons to consider continuing work after the age of 63 also varied according to the physical workload. Own health was stated as a reason for continuing work, especially by employees whose work involved a high physical workload. At the same time, financial gain; meaningful, interesting and challenging work; and flexible working hours were more common reasons for those whose work was physically less demanding.

In Finland, about one in four employees performs physically strenuous work [4]. Thus it is important to balance the physical workload, for example through developing work, work tools and the work environment, in order to get people to work for longer. These actions are especially needed in the construction in- dustry, hotels and restaurants, health and social work, and the agricultural sector [4].

\section{References}

[1] J. Kannisto, Effective retirement age in the Finnish earnings related pension scheme, Finnish Centre for Pension, Statistical report $2 / 2011$

[2] M. Karpansalo, M, P. Manninen, T.A. Lakka, J. Kauhanen, R. Rauramaa and J.T. Salonen, Physical workload and risk of early retirement: prospective population-base study among middle-aged men, JOEM; 2002; 44(10)930-9.

[3] T. Kauppinen, R. Hanhela, I. Kandolin, A. Karjalainen, A. Kasvio, M. Perkiö-Mäkelä, E. Priha, J. Toikkanen and M. Viluksela, ed., Work and Health in Finland 2009, Helsinki, Finnish Institute of Occupational Health, 2010, (in Finnish with English summary).

[4] M. Perkiö-Mäkelä, M. Hirvonen, AL. Elo, I. Kandolin, K. Kauppinen, T. Kauppinen, R. Ketola, T. Leino, P. Manninen, S. Miettinen, R. Reijula, S. Salminen, M. Toivanen, S Tuomivaara, M. Vartia, S. Venäläinen and M. Viluksela, Finnish national Work and Health survey 2009. Helsinki: Finnish Institute of Occupational Health [network document] 2010, available http://www.ttl.fi/tyojaterveys (in Finnish).

[5] TI. van den Berg, L.A. Elders, A. Burdorf, Influence of Health and Work on Early Retirement, Journal of Occupational and Environmental Medicine 2010;52(6):576-583 